\title{
Bone marrow mesenchymal stem cells promote osteosarcoma cell proliferation and invasion
}

\author{
Fu-Xiang Yu', Wei-Jian Hu', Bin He', Yi-Hu Zheng ${ }^{1}$, Qi-Yu Zhang ${ }^{1}$ and Lin Chen²*
}

\begin{abstract}
Background: Bone marrow-derived stem cells (BMSCs) are locally adjacent to the tumor tissues and may interact with tumor cells directly. The purpose of this study was to explore the effects of BMSCs on the proliferation and invasion of osteosarcoma cells in vitro and the possible mechanism involved.

Methods: BMSCs were co-cultured with osteosarcoma cells, and CCK-8 assay was used to measure cell proliferation. The ELISA method was used to determine the concentration of stromal cell-derived factor-1 (SDF-1) in the supernatants. Reverse transcription polymerase chain reaction (RT-PCR) was performed to detect the expression of CXCR4 in osteosarcoma cells and BMSCs. Matrigel invasion assay was performed to measure tumor cell invasion.

Results: SDF-1 was detected in the supernatants of BMSCs, but not in osteosarcoma cells. Higher CXCR4 mRNA levels were detected in the osteosarcoma cell lines compared to BMSCs. In addition, conditioned medium from BMSCs can promote the proliferation and invasion of osteosarcoma cells, and AMD3100, an antagonist for CXCR4, can significantly downregulate these growth-promoting effects.

Conclusions: BMSCs can promote the proliferation and invasion of osteosarcoma cells, which may involve the SDF-1/CXCR4 axis.
\end{abstract}

Keywords: Bone marrow mesenchymal stem cells, Osteosarcoma

\section{Background}

It has been increasingly recognized that cancer cells actively recruit stromal cells into tumors and this recruitment is essential for the generation of a microenvironment that promotes tumor growth [1]. Since the stroma cells can stimulate tumor growth and invasiveness, stromal cells play an active role in cancer progression, induce chemotherapy resistance, and inhibit cancer cell apoptosis [2-5]. Organs have abundant stroma surrounding them, and tumor-stroma interactions play a critical role in tumor progression [6]. Although the exact mechanisms of tumorstroma interactions remain unclear, some chemokines, including hepatocyte growth factor, epidermal growth factor, vascular endothelial growth factor, and stromal cell-derived factor-1 (SDF-1), have been shown to be involved in the interaction $[7,8]$.

\footnotetext{
* Correspondence: yfxbmu@sina.com

${ }^{2}$ Department of Pathology, The First Affiliated Hospital of Wenzhou Medical University, Nan Bai Xiang Street, Ouhai District, Wenzhou, Zhejiang 325002, China

Full list of author information is available at the end of the article
}

SDF-1 belongs to the CXC chemokine family and is a ligand for CXCR4. SDF-1 is expressed in stromal cells [9], and CXCR4 expression has been found in many cancer types, including breast, ovary, kidney, prostate, and stomach cancer tissue and cell lines [10-12]. In addition, it has been demonstrated that the SDF-1/CXCR4 receptor ligand system plays an important role in carcinoma progression by promoting tumor cell migration and angiogenesis $[13,14]$.

The interactions between mesenchymal stem cells from bone marrow and malignant tumors from the breast, prostate, ovaries, and stomach have been recently described $[10,15]$. Bone marrow-derived stem cells (BMSCs) are locally adjacent to the tumor tissues and may interact with tumor cells directly. However, the ability of BMSCs to promote tumor cell proliferation remains controversial. It has been reported that BMSCs can promote breast, prostate, non-small lung, and glioblastoma cancer cell growth in vivo [16-18]. In contrast, several reports have shown an anti-tumor effect of mesenchymal stem cells. Khakoo et al. used systemic injection of mesenchymal 
stem cells to inhibit the growth of a subcutaneous Kaposi sarcoma xenotransplant [19]. Moreover, the co-implantation of breast cancer cells with mesenchymal stem cells results in tumor growth inhibition and a reduction of metastasis in vivo [20]. However, the impact of BMSCs, which are a type of local mesenchymal stem cell, on proliferation and invasion of osteosarcoma has not been reported to date. Therefore, in this study, we determined whether BMSCs can promote the growth and invasion of osteosarcoma and sought to explore the mechanism responsible for these observed effects.

\section{Methods}

\section{Cell lines and reagents}

Human osteosarcoma cell lines MG-63 and OS732 were purchased from the Chinese Academy of Sciences (Shanghai, China). Dulbecco's modified Eagle's medium (DMEM) and fetal bovine serum (FBS) were provided by Gibco (Grand Island, NY, USA), and recombinant human CXCL12 (SDF-1) was purchased from R\&D systems (Minneapolis, MN, USA). AMD3100, a chemokine receptor antagonist for CXCR4, and Matrigel were obtained from Sigma-Aldrich (St. Louis, MO, USA). The fluorochrome-conjugated antibodies used for immunostaining - anti-CD45-APC, antiCD29-PE, and anti-CD90-FITC - and appropriate negative controls were from BD (San Diego, CA, USA).

\section{Isolation of human BMSCs}

Bone marrow was obtained from healthy persons who had provided written informed consent. This process was approved by the institutional review board of the First Affiliated Hospital of Wenzhou Medical University. A solution of density of $1.073 \mathrm{~g} / \mathrm{mL}$ by dilution of Percoll was added to the bottom of the separating tube. Then, the fresh bone marrow of $20 \mathrm{~mL}$ was added to Percoll in a volume ratio of 1:1 gently. Centrifugation was carried out at room temperature at 3,000 rpm for $30 \mathrm{~min}$. The white cell band between the two layers was transferred, and the pelleted cells were washed two times with the medium without FBS. Finally, cells were resuspended and grown in low-glucose $(1,000 \mathrm{mg} / \mathrm{L}) \mathrm{DMEM}$ (L-DMEM) containing 20\% FBS, $100 \mu \mathrm{g} / \mathrm{L}$ penicillin, and $100 \mu \mathrm{g} / \mathrm{L}$ streptomycin in a humidified environment with $5 \% \mathrm{CO}_{2}$ at $37^{\circ} \mathrm{C}$. After $48 \mathrm{~h}$, unattached cells were washed and removed. The cells were then grown in a humidified incubator at $37^{\circ} \mathrm{C}$ for an additional 4 weeks. Before phenotype analysis by flow cytometry, cells were fixed and permeabilized by a Cytofix/Cytoperm reagent (Becton Dickinson PharMingen, San Jose, CA, USA) after being harvested from six-well assay plates. Then, they were indicated by a panel of antibodies including PE-conjugated CD29 antibody, FITC-conjugated CD90 antibody, and APC-conjugated CD45 antibody.

\section{Differentiation of human BMSCs into adipocytes}

BMSCs were cultured to confluence in $35-\mathrm{mm}$ dishes containing DMEM. The medium was then removed and fresh DMEM was added containing $0.5 \mathrm{mM}$ IBMX, $1.0 \mu \mathrm{M}$ dexamethasone, and $300 \mathrm{nM}$ insulin. The cells were cultured in the differentiation medium for 2 days, and then the medium was changed every 2 days with DMEM containing only $300 \mathrm{nM}$ insulin for a total of two times. After this step, the cells were incubated in DMEM without any additives, which was changed every 10 days. Fully differentiated adipocytes were observed by light microscopy based on morphology. Oil red O staining was used to detect fat droplets for the various treatments as described above.

\section{Transwell co-culture system and CXCR4 antagonist treatment}

BMSCs were cultured in apical compartments of transwells (transwell insert $0.4 \mu \mathrm{m}$; Millipore, Billerica, MD, USA) with osteosarcoma cells grown in the basal compartment of the plate (Millipore). BMSCs were seeded onto the upper layer of transwells without direct contact with osteosarcoma cells. Osteosarcoma cells were seeded onto the lower layer of transwells. CXCR4 antagonist, AMD3100 (100 ng/mL), was added into the wells when drug experiment was needed. All cells were grown in L-DMEM supplemented with $10 \% \mathrm{FBS}$ at $37^{\circ} \mathrm{C}$ in $5 \% \mathrm{CO}_{2}$. As a control, the same osteosarcoma cells were seeded instead of BMSCs onto the upper layer. After culturing the cells for $72 \mathrm{~h}$, cell proliferation was analyzed using a CCK-8 kit (Dojindo, Kumamoto, Japan) following the manufacturer's instructions.

\section{Proliferation assay}

The CCK-8 kit solution was added to each well, the cells were incubated for another $2 \mathrm{~h}$, and the absorbance at $450 \mathrm{~nm}$ was measured by using a spectrophotometer. The amount of the formazan dye, generated by the activities of dehydrogenases in cells, is directly proportional to the number of living cells. The proliferation rate (\%) of cells was calculated using the following equation: $1-(A$ of control $-A$ of BMSCs) / ( $A$ of control $-A$ of osteosarcoma cells) $\times 100 \%$.

\section{Invasion assay}

Invasion assay was performed using Boyden chambers with inserts (pore size: $8 \mu \mathrm{m}$ ) coated with Matrigel in 24-well plates. Briefly, osteosarcoma cells $\left(4 \times 10^{5}\right.$ cells $\left./ \mathrm{mL}\right)$ were suspended in $250 \mu \mathrm{L}$ medium containing $2 \%$ FBS in the upper chamber, which was pre-coated with $15 \mu \mathrm{L}$ Matrigel $(0.5 \mu \mathrm{g} / \mathrm{mL})$. BMSCs were seeded onto the lower layer of transwells at a density of $2 \times 10^{5}$ cells/well. The co-culture system was incubated at room temperature for $15 \mathrm{~min}$. The control group consisted of plates with 
medium containing $2 \% \mathrm{FBS}$ and osteosarcoma cells in the upper chamber only. The plates were incubated for $24 \mathrm{~h}$ at $37^{\circ} \mathrm{C}$. Cells on the upper side of the filters were removed with cotton-tipped swabs, and invaded cells were fixed with $4 \%$ paraformaldehyde, washed with PBS, air dried, and stained with crystal violet for $30 \mathrm{~min}$. They were then rinsed several times with distilled water. The number of invading cells was counted in five random microscopic fields.

\section{ELISA assay}

After culturing cells for $72 \mathrm{~h}$ at $37^{\circ} \mathrm{C}$ containing $5 \% \mathrm{CO}_{2}$ in a humidified incubator, the culture medium was collected separately and centrifuged at 1,000 rpm for $5 \mathrm{~min}$ to remove debris. The supernatants were then frozen at $-80^{\circ} \mathrm{C}$ for further assessment by ELISA. ELISA was performed using the human CXCL12/SDF-1 kit (R\&D Systems, Minneapolis, MN, USA) according to the manufacturer's instructions.

\section{Reverse transcription polymerase chain reaction}

Total RNA was extracted from cultured cells using Trizol (Invitrogen, Carlsbad, CA, USA). The cDNA was synthesized using a random primer from $1 \mu \mathrm{g}$ of total RNA with the Revert Aid First Strand cDNA Synthesis Kit according the to manufacturer's instructions (Fermentas, Glen Burnie, MD, USA). The following primers were used for reverse transcription polymerase chain reaction (RT-PCR): human SDF-1 (sense, 5' -gctttgagtgactgggtt-3'; antisense, $5^{\prime}$-gtggcaagatgatggttt- $3^{\prime}$ ), PCR product size: $124 \mathrm{bp}$; human CXCR4 (sense, $5^{\prime}$-gaagctgttggctgaaaagg-3'; antisense, $5^{\prime}$-gagtcgatgctgatcccaat-3'), PCR product size: $345 \mathrm{bp}$; and human beta-actin (sense, $5^{\prime}$-actcttccagccttccttc-3'; antisense, $5^{\prime}$-tgtcaccttcaccgttcc-3'), PCR product size: $516 \mathrm{bp}$. PCR was performed following the manufacturer's instructions. The cycling conditions were $3 \mathrm{~min}$ at $94^{\circ} \mathrm{C}$, followed by 30 cycles of denaturation at $94^{\circ} \mathrm{C}$ for $30 \mathrm{~s}$, annealing at $54^{\circ} \mathrm{C}$ for $30 \mathrm{~s}$, and extension at $72^{\circ} \mathrm{C}$ for $60 \mathrm{~s}$. Amplified DNA fragments were resolved by electrophoresis on $1 \%$ agarose gels containing ethidium bromide.

\section{Statistical analysis}

Data were expressed as means \pm standard deviation (SD) and analyzed using analysis of variance (ANOVA). $P<0.05$ was considered statistically significant.

\section{Results}

\section{Identification of BMSCs}

Primary human BMSCs were spindle-shaped and adherent to the dish (Figure 1A). Several BMSC markers were confirmed by flow cytometric analysis, including CD29, CD90, and CD45 $(97.22 \pm 1.94,94.91 \pm 3.88$, and $2.22 \pm$ $0.21 \%$ positivity, respectively) (Figure $1 \mathrm{~B}$ ). The CD marker analysis of BMSCs was consistent with typical mesenchymal stem cells. After differentiation, the accumulated adipocytes in BMSCs were detected by oil red $\mathrm{O}$ staining for the various treatments. Most of the BMSCs differentiated into adipocytes successfully, and Oil red $\mathrm{O}$ staining detected numerous fat droplets in the cytoplasm of adipocytes.

\section{Effect of BMSCs on the proliferation and invasion of osteosarcoma cells}

Using a cell co-culture system, we found that BMSCs promote the proliferation of osteosarcoma cells (Figure 2A). The number of osteosarcoma MG-63 and OS732 cells cultured with BMSCs in the system was significantly higher than the cells grown in the absence of BMSCs. Moreover, the invasion of osteosarcoma cells incubated with the BMSC supernatant was enhanced (Figure 2B).

\section{Secretion of SDF- 1 by BMSCs}

The amounts of SDF-1 secreted by BMSCs and osteosarcoma cells were determined by ELISA. The concentration of SDF-1 in the BMSC supernatant was nearly $600 \mathrm{pg} / \mathrm{mL}$. Importantly, a very low concentration of SDF-1 was detected in the supernatant of osteosarcoma cells (Figure 3A). These data confirmed that BMSCs, but not osteosarcoma cell lines, secret SDF-1.

\section{Expression of SDF-1 and CXCR4 in cultured osteosarcoma} cell lines and BMSCs

We evaluated the expression of SDF-1 and CXCR4 by RT-PCR in cultured cells. BMSCs exhibited a higher expression of SDF-1 compared to MG-63 and OS732 cells (Figure 3B). However, these two osteosarcoma cell lines showed a higher expression of CXCR4 compared to BMSCs (Figure 3C).

\section{Effects of SDF-1 on the proliferation of osteosarcoma cell lines}

SDF-1 enhanced the proliferation of osteosarcoma cells in a dose-dependent manner compared to controls (Figure 4A). The CXCR4 antagonist AMD3100 significantly blocked SDF-1-induced proliferation $(P<0.05)$ but did not inhibit MG-63 and OS732 basal cell growth in the absence of SDF-1 (Figure 4B).

\section{Effects of BMSCs on the proliferation of osteosarcoma cells in the presence of AMD3100}

The effect of BMSCs on MG-63 and OS732 cell growth in the presence of AMD3100 was also determined using the CCK- 8 assay. We found that BMSCs enhanced the proliferation of both osteosarcoma cell lines, which were significantly reduced by the addition of AMD3100 in a dose-dependent manner $(P<0.05)$ (Figure $4 \mathrm{C})$. 
A

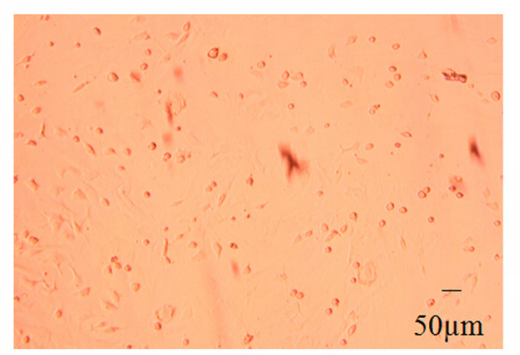

Primary Human BMSCs (CD29+/CD90+/CD45-)

B
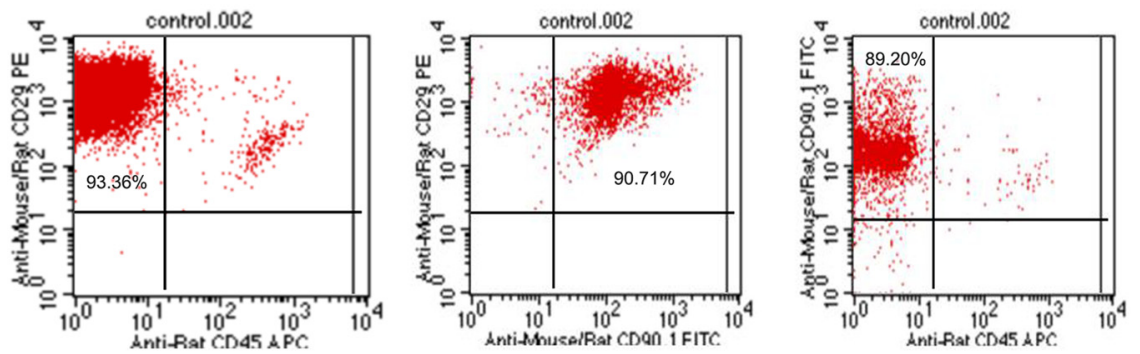

C

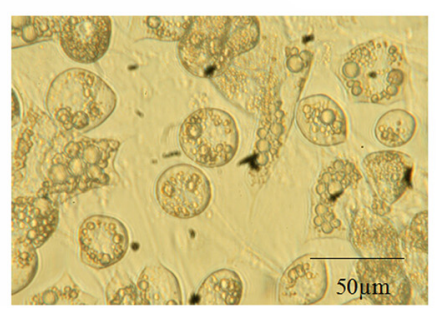

D

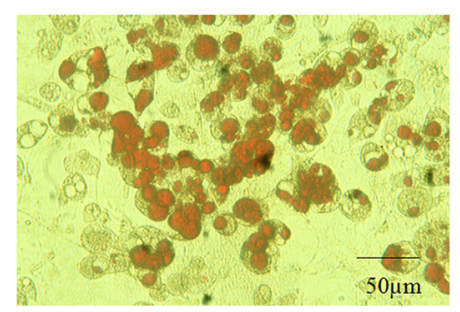

Figure 1 Identification of bone marrow-derived stem cells. (A) The phenotype of BMSCs isolated from human bone marrow tissue (on the first day; 100x magnification fold). (B) The expression of CD45, CD29, and CD90 in isolated BMSCs. (C) The fat droplets were observed in the cytoplasm of adipocytes at 400x magnification. (D) The fat droplets were stained with Oil red O. Image is magnified $200 \times$.

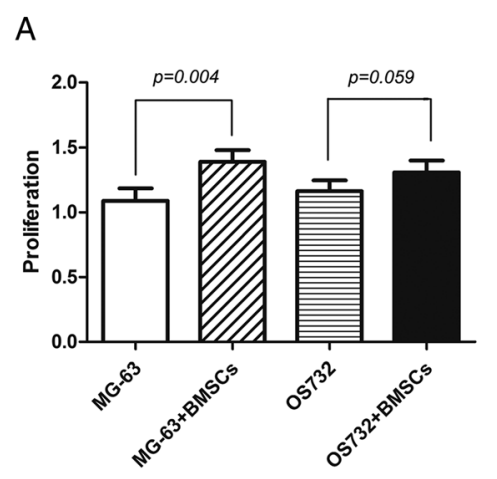

B

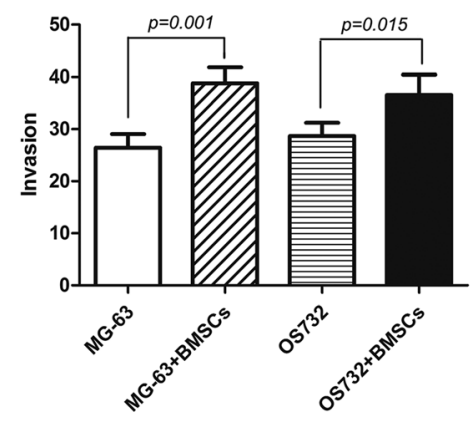

Figure 2 Effect of BMSCs on the proliferation and invasion of osteosarcoma cells. (A) After co-culturing BMSCs with osteosarcoma cells for $72 \mathrm{~h}$, the proliferation of osteosarcoma cells was examined using the CCK-8 assay. The proliferation of MG-63 and OS732 cells co-cultured with BMSCs was significantly increased compared to that of the respective cells cultured alone. (B) BMSCs were co-cultured with osteosarcoma cells for $72 \mathrm{~h}$, and the percentage of osteosarcoma cell invasion was examined under a microscope. The invasion of MG-63 and OS732 cells was significantly greater in the presence of BMSCs compared to control cells. 


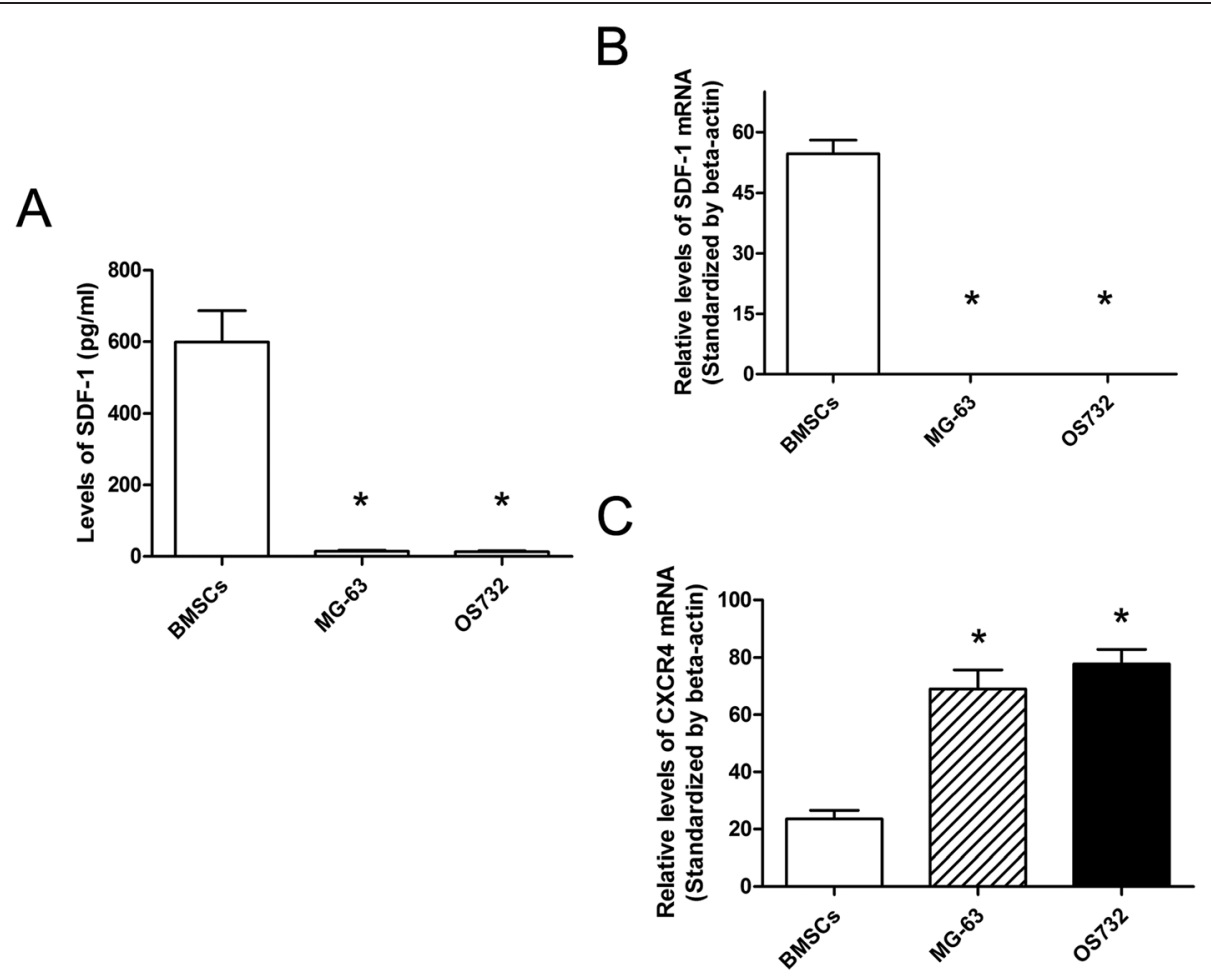

Figure 3 SDF-1 secretion and SDF-1 and CXCR4 expression. (A) The SDF-1 concentration in the BMSC supernatant as detected by ELISA. BMSCs had significantly higher levels of SDF-1 compared to MG-63 and OS732 cells. (B) The RT-PCR analysis of SDF-1 mRNA expression in osteosarcoma cell lines and BMSCs. (C) The RT-PCR analysis of CXCR4 mRNA expression in osteosarcoma cell lines and BMSCs. $\left({ }^{*} P<0.01\right.$ compared to the BMSCs).

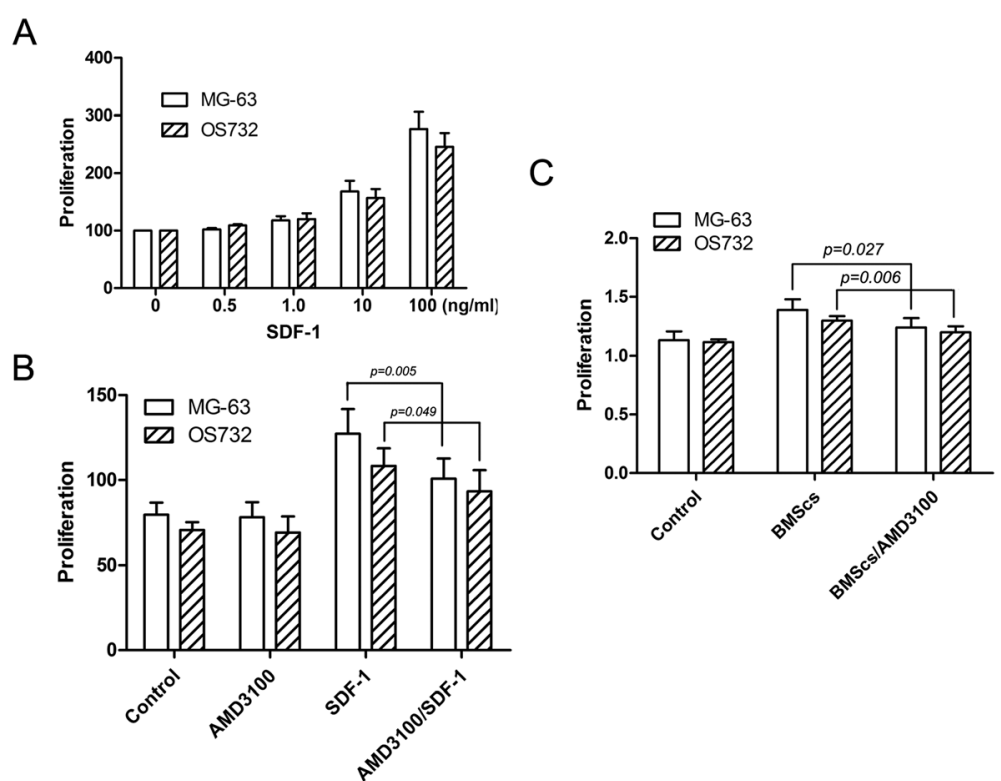

Figure 4 Effects of SDF-1 on the proliferation of osteosarcoma cell lines. (A) SDF-1 promotes the proliferation of osteosarcoma cells in a dose-dependent manner. (B) AMD3100 partially blocks SDF-1-mediated proliferation. (C) AMD3100 downregulates the effects of BMSCs on osteosarcoma cell line proliferation. 


\section{Discussion}

The interaction between the tumor and tumor-associated stroma has been reported in many studies, and the importance of the local tumor microenvironment for tumor progression has been recognized for many years $[21,22]$. This study demonstrated that BMSCs promote osteosarcoma cell proliferation and invasion in vitro. Furthermore, we demonstrated that the SDF-1/CXCR4 axis plays an important role in mediating the tumor-promoting effect.

Since BMSCs are derived from bone marrow tissue that is abundant in the tissues adjacent to osteosarcoma, it is very important for their capacity to promote osteosarcoma cell growth. We first found that BMSCs, but not osteosarcoma cells, secret SDF-1. SDF-1 is a secreted chemokine that is released into the interstitial space, where it acts on cells in the local microenvironment in a paracrine fashion to stimulate directional migration of hematopoietic and nonhematopoietic normal and malignant cells [23]. SDF-1 exerts a variety of biological functions, including the regulation of angiogenesis and inhibition of apoptosis as well as tumor growth, migration, and invasion promoting effects through the SDF-1/CXCR4 receptor ligand axis [24-26]. Furthermore, Brand et al. demonstrated that SDF-1 stimulation induces a significant increase in VEGF protein levels in the colorectal cancer line HT-29 [27]. SDF-1 has also been demonstrated to play a role in tumors, including breast cancer, melanoma, ovarian cancer, gastric cancer, and other carcinomas [12].

We also assessed the expression of CXCR4 in the two osteosarcoma cell lines using RT-PCR and found that the mRNA levels were elevated compared to controls. In contrast, CXCR4 mRNA levels were very low in BMSCs. Importantly, these results were consistent with previous studies $[13,28]$. We also found that the SDF-1/CXCR4 axis plays an important role in the proliferation of osteosarcoma cells. In this study, we demonstrated that recombinant SDF-1 could significantly promote the proliferation of osteosarcoma cells. Blocking the receptor with AMD3100 was sufficient for preventing SDF-1-mediated proliferation in MG-63 and OS732 cells. It has been further reported that CXCR4 signaling in osteosarcoma cell lines can promote MG-63 and OS732 proliferation [29]. Taken together, therefore, these data suggest that CXCR4 is a potential therapeutic target in osteosarcoma.

Moreover, we found that BMSCs stimulate the invasive behavior of osteosarcoma cells. An invasion assay using a Matrigel-coated invasion chamber showed that BMSCs stimulated invasion of osteosarcoma cells and that these effects were inhibited by the addition of the CXCR4 inhibitor AMD3100. Therefore, SDF-1 plays a critical role in promoting the invasion of osteosarcoma cells. However, although the BMSC-induced proliferation was inhibited by AMD3100, proliferation was still higher than the control. Therefore, other factors, such as matrix metalloproteinase-9 (MMP-9), MMP-2, and vascular endothelial growth factor $[10,30]$, may also be involved in promoting the proliferation and invasion of osteosarcoma cells. It has been shown that myofibroblastderived SDF-1 recruits endothelial progenitor cells to sites of carcinomas, thereby enhancing angiogenesis and tumor growth [31]. Therefore, BMSC-derived SDF-1 may be partially responsible for the proliferation and invasion of osteosarcoma cells.

\section{Conclusions}

The aim of this study was to gain a better understand of the mechanisms related to osteosarcoma growth and invasion. Despite advances in surgical and medical therapies, overall survival rate for patients with osteosarcoma remains low $[32,33]$. Therefore, a better understanding of the fundamental nature of this cancer is needed to improve clinical outcome. Our finding that local stem cells adjacent to osteosarcoma cells are involved in tumor growth and invasion may be useful for osteosarcoma therapy, as these results suggest that the bone marrow tissue surrounding the osteosarcoma tissue should be resected completely. Future studies need to confirm these findings.

\section{Competing interests \\ The authors declare that they have no competing interests.}

\section{Authors' contributions}

FY and WH carried out the study. BH performed the statistical analysis. YZ contributed to the writing of the manuscript. QZ participated in the design of the study. LC conceived the study and participated in its design and coordination. All authors read and approved the final manuscript.

\section{Authors' information}

The first author is Dr. Fu-Xiang Yu.

\section{Acknowledgements}

This study was sponsored in part by a grant from Zhejiang Province Key Surgery projects (Zhejiang High-Tech 2008-255), Zhejiang Provincial Top Key Discipline in Surgery, and Zhejiang Province Scientific Research projects of education (Y201326678).

\section{Author details}

'Department of General Surgery, The First Affiliated Hospital of Wenzhou Medical University, Nan Bai Xiang Street, Ouhai District, Wenzhou, Zhejiang 325002, China. ${ }^{2}$ Department of Pathology, The First Affiliated Hospital of Wenzhou Medical University, Nan Bai Xiang Street, Ouhai District, Wenzhou, Zhejiang 325002, China.

Received: 12 May 2014 Accepted: 17 January 2015

Published online: 15 February 2015

\section{References}

1. Bhowmick NA, Neilson EG, Moses HL. Stromal fibroblasts in cancer initiation and progression. Nature. 2004;432(7015):332-7.

2. Armstrong T, Packham G, Murphy LB, Bateman AC, Conti JA, Fine DR, et al. Type I collagen promotes the malignant phenotype of pancreatic ductal adenocarcinoma. Clin Cancer Res. 2004;10(21):7427-37.

3. Bachem MG, Schunemann M, Ramadani M, Siech M, Beger $H$, Buck A, et al. Pancreatic carcinoma cells induce fibrosis by stimulating proliferation and matrix synthesis of stellate cells. Gastroenterology. 2005;128(4):907-21. 
4. Miyamoto H, Murakami T, Tsuchida K, Sugino H, Miyake H, Tashiro S. Tumor-stroma interaction of human pancreatic cancer: acquired resistance to anticancer drugs and proliferation regulation is dependent on extracellular matrix proteins. Pancreas. 2004;28(1):38-44.

5. Muerkoster S, Wegehenkel K, Arlt A, Witt M, Sipos B, Kruse ML, et al. Tumor stroma interactions induce chemoresistance in pancreatic ductal carcinoma cells involving increased secretion and paracrine effects of nitric oxide and interleukin-1 beta. Cancer Res. 2004;64(4):1331-7.

6. Ohuchida K, Mizumoto K, Murakami M, Qian LW, Sato N, Nagai E, et al. Radiation to stromal fibroblasts increases invasiveness of pancreatic cancer cells through tumor-stromal interactions. Cancer Res. 2004;64(9):3215-22.

7. Daly AJ, Mcllreavey L, Irwin CR. Regulation of HGF and SDF-1 expression by oral fibroblasts-implications for invasion of oral cancer. Oral Oncol. 2008;44(7):646-51.

8. Kajita T, Ohta Y, Kimura K, Tamura M, Tanaka Y, Tsunezuka Y, et al. The expression of vascular endothelial growth factor $C$ and its receptors in non-small cell lung cancer. Br J Cancer. 2001;85(2):255-60.

9. Pablos JL, Amara A, Bouloc A, Santiago B, Caruz A, Galindo M, et al. Stromal-cell derived factor is expressed by dendritic cells and endothelium in human skin. Am J Pathol. 1999;155(5):1577-86

10. Muehlberg FL, Song YH, Krohn A, Pinilla SP, Droll LH, Leng X, et al. Tissue-resident stem cells promote breast cancer growth and metastasis. Carcinogenesis. 2009;30(4):589-97.

11. Taichman RS, Cooper C, Keller ET, Pienta KJ, Taichman NS, McCauley LK. Use of the stromal cell-derived factor-1/CXCR4 pathway in prostate cancer metastasis to bone. Cancer Res. 2002;62(6):1832-7.

12. Schrader AJ, Lechner $\mathrm{O}$, Templin M, Dittmar KE, Machtens S, Mengel M, et al. CXCR4/CXCL12 expression and signalling in kidney cancer. Br J Cancer. 2002:86(8):1250-6.

13. Marchesi F, Monti P, Leone BE, Zerbi A, Vecchi A, Piemonti L, et al. Increased survival, proliferation, and migration in metastatic human pancreatic tumor cells expressing functional CXCR4. Cancer Res. 2004;64(22):8420-7.

14. Mori T, Doi R, Koizumi M, Toyoda E, Ito D, Kami K, et al. CXCR4 antagonist inhibits stromal cell-derived factor 1-induced migration and invasion of human pancreatic cancer. Mol Cancer Ther. 2004;3(1):29-37.

15. Wang J, Sun Y, Song W, Nor JE, Wang CY, Taichman RS. Diverse signaling pathways through the SDF-1/CXCR4 chemokine axis in prostate cancer cell lines leads to altered patterns of cytokine secretion and angiogenesis. Cell Signal. 2005;17(12):1578-92.

16. Kucerova L, Altanerova V, Matuskova M, Tyciakova S, Altaner C. Adipose tissue-derived human mesenchymal stem cells mediated prodrug cancer gene therapy. Cancer Res. 2007;67(13):6304-13.

17. Prantl L, Muehlberg F, Navone NM, Song YH, Vykoukal J, Logothetis CJ, et al. Adipose tissue-derived stem cells promote prostate tumor growth. Prostate. 2010;70(15):1709-15

18. Yu JM, Jun ES, Bae YC, Jung JS. Mesenchymal stem cells derived from human adipose tissues favor tumor cell growth in vivo. Stem Cells Dev. 2008;17(3):463-73.

19. Khakoo AY, Pati S, Anderson SA, Reid W, Elshal MF, Rovira II, et al. Human mesenchymal stem cells exert potent antitumorigenic effects in a model of Kaposi's sarcoma. J Exp Med. 2006;203(5):1235-47.

20. Qiao L, Xu ZL, Zhao TJ, Ye LH, Zhang XD. Dkk-1 secreted by mesenchymal stem cells inhibits growth of breast cancer cells via depression of Wnt signalling. Cancer Lett. 2008;269(1):67-77.

21. De Wever $\mathrm{O}$, Mareel M. Role of tissue stroma in cancer cell invasion. J Pathol. 2003;200(4):429-47.

22. Liotta LA, Kohn EC. The microenvironment of the tumour-host interface. Nature. 2001;411(6835):375-9.

23. Burger JA, Kipps TJ. CXCR4: a key receptor in the crosstalk between tumor cells and their microenvironment. Blood. 2006;107(5):1761-7.

24. Balkwill F. Cancer and the chemokine network. Nat Rev Cancer. 2004;4 (7):540-50.

25. Homey B, Muller A, Zlotnik A. Chemokines: agents for the immunotherapy of cancer? Nat Rev Immunol. 2002;2(3):175-84.

26. Murphy PM. Chemokines and the molecular basis of cancer metastasis. $N$ Engl J Med. 2001;345(11):833-5.

27. Brand S, Dambacher J, Beigel F, Olszak T, Diebold J, Otte JM, et al. CXCR4 and CXCL12 are inversely expressed in colorectal cancer cells and modulate cancer cell migration, invasion and MMP-9 activation. Exp Cell Res. 2005:310(1):117-30.
28. Koshiba T, Hosotani R, Miyamoto Y, Ida J, Tsuji S, Nakajima S, et al. Expression of stromal cell-derived factor 1 and CXCR4 ligand receptor system in pancreatic cancer: a possible role for tumor progression. Clin Cancer Res. 2000;6(9):3530-5.

29. Billadeau DD, Chatterjee S, Bramati P, Sreekumar R, Shah V, Hedin K, et al. Characterization of the CXCR4 signaling in pancreatic cancer cells. Int J Gastrointest Cancer. 2006;37(4):110-9.

30. Nagakawa Y, Aoki T, Kasuya K, Tsuchida A, Koyanagi Y. Histologic features of venous invasion, expression of vascular endothelial growth factor and matrix metalloproteinase-2 and matrix metalloproteinase-9, and the relation with liver metastasis in pancreatic cancer. Pancreas. 2002;24(2):169-78.

31. lyengar P, Combs TP, Shah SJ, Gouon-Evans V, Pollard JW, Albanese C, et al. Adipocyte-secreted factors synergistically promote mammary tumorigenesis through induction of anti-apoptotic transcriptional programs and proto-oncogene stabilization. Oncogene. 2003:22(41):6408-23.

32. Chou AJ, Geller DS, Gorlick R. Therapy for osteosarcoma: where do we go from here? Paediatr Drugs. 2008;10(5):315-27.

33. Broadhead ML, Clark JC, Myers DE, Dass CR, Choong PF. The molecular pathogenesis of osteosarcoma: a review. Sarcoma. 2011;2011:959248.

\section{Submit your next manuscript to BioMed Central and take full advantage of:}

- Convenient online submission

- Thorough peer review

- No space constraints or color figure charges

- Immediate publication on acceptance

- Inclusion in PubMed, CAS, Scopus and Google Scholar

- Research which is freely available for redistribution 